\title{
DNA Microarray Analysis of Gene Expression in Eutopic Endometrium from Patients with Endometriosis
}

\author{
Kyu Ri Hwang1,2, Young Min Choi ${ }^{2,3 *}$, Jin Ju Kim ${ }^{2,4}$, Hye Won Jeon ${ }^{1,2}$, Min A. Hong ${ }^{3}$ \\ ${ }^{1}$ Department of Obstetrics and Gynecology, SMG-SNU Boramae Medical Center, Seoul, South Korea \\ ${ }^{2}$ Department of Obstetrics and Gynecology, Seoul National University College of Medicine, Seoul, South Korea \\ ${ }^{3}$ The Institute of Reproductive Medicine and Population, Medical Research Center, Seoul National University College of Medicine, \\ Seoul, South Korea \\ ${ }^{4}$ Department of Obstetrics and Gynecology, Healthcare System Gangnam Center, Seoul National University Hospital, Seoul, \\ South Korea \\ Email: *ymchoi@snu.ac.kr
}

\begin{abstract}
How to cite this paper: Hwang, K.R., Choi, Y.M., Kim, J.J., Jeon, H.W. and Hong, M.A. (2017) DNA Microarray Analysis of Gene Expression in Eutopic Endometrium from Patients with Endometriosis. Advances in Reproductive Sciences, 5, 75-96. https://doi.org/10.4236/arsci.2017.54009
\end{abstract}

Received: September 6, 2017

Accepted: November 24, 2017

Published: November 27, 2017

Copyright (C) 2017 by authors and Scientific Research Publishing Inc. This work is licensed under the Creative Commons Attribution International License (CC BY 4.0).

http://creativecommons.org/licenses/by/4.0/ Open Access

\begin{abstract}
Pathogenesis of the endometriosis is complex and the etiology is still unclear. The objective of this study was to examine that endometrial gene expression in late secretory phase endometrium differs between patients with and without endometriosis. Five patients with proven advanced-stage endometriosis and 5 controls underwent endometrial biopsy in the late secretory phase. Analysis of eutopic endometrial gene expression was performed using Affymetrix gene arrays and differentially expressed genes were assigned to gene ontology groups based on overrepresented analysis using Database for Annotation, Visualization, and Integrated Discovery software. Four hundred sixty two genes were identified as up-regulated such as matrix metalloproteinase 10, cytochrome P450 family 24 subfamily A polypeptide 1 , matrix metalloproteinase 3 , chemokine (C-C motif) ligand 20, Rho family GTPase 1, interleukin 1-beta, and insulin-like growth factor binding protein 1 . Six hundred forty three genes were down-regulated in all endometriotic samples. A lot of genes related with metabolic process, cellular ketone metabolic process and ncRNA metabolic processing were included. Expression patterns of selected five genes were validated by quantitative real time PCR. The results of this analysis support that the eutopic endometrium from patients with advanced-stage endometriosis has distinct gene expression profile from eutopic endometrium of control without endometriosis.
\end{abstract}

\section{Keywords}

Endometriosis, Eutopic Endometrium, Microarray, Gene Expression Profiling 


\section{Introduction}

Endometriosis is defined as the presence of endometrial tissue outside the uterus, and this condition affects $6 \%-10 \%$ of women of reproductive age. Endometriosis causes diverse clinical manifestations including subfertility, pelvic pain, and dysmenorrhea, and has a significant detrimental impact on quality of life and work productivity [1] [2]. Although the etiology of endometriosis remains elusive, retrograde menstruation into the peritoneal cavity during menstruation is widely accepted as a major contributing factor in the pathogenesis of this disease. However, backflow of menstrual materials through the fallopian tubes into the pelvic cavity is a common phenomenon that occurs in up to $90 \%$ of menstruating women with patent fallopian tubes [3]. Therefore, it has yet to be determined why endometriosis affects only a certain group of women. Furthermore, this finding suggests that there may be immunological and genetic factors that determine a woman's susceptibility to endometriosis.

Endometriosis is a major cause of infertility and women with endometriosis are twice as likely to have infertility [4] [5]. The correlation between endometriosis and infertility has not been clearly verified; damage to the anatomical relationship between the ovaries and the fallopian tubes due to serious endometriosis may be strongly suspected as the cause of infertility, but the association of a mild condition of endometriosis that is not accompanied by such anatomical damage with infertility is very controversial. The above finding suggests that there are endometrial abnormalities that may obstruct embryo implantation, which may trigger infertility.

In the past, gene expression research was able to work on only one gene each time, but the introduction of DNA microarray technology enabled rapid and concurrent examination of mutual gene expression changes under different conditions and in different types of cells [6]. A recent report that compared gene expression patterns in the uterus linings of an endometriosis group and a control group without the disease presented that the expression of certain genes in the endometriosis group significantly decreased during the embryo implantation, which may disturb implantation and result in infertility [7]. It also added that the expression of other genes in the endometriosis group significantly increased during the embryo implantation and such increased expression may be associated with the onset of endometriosis. Further, there was research reporting that endometriosis patients had aberrant expressions of a certain gene associated with the generation of the disease and impact on the abdominal cavity and other tissues and that such patients' normal uterus linings may look histologically normal but were biochemically abnormal [8] [9] [10]. Based on the above research results, it is inferred that relative over-expression or under-expression of certain genes in endometriosis patients' uterus linings may generate the disease itself or hinder embryo implantation during the implantation period. This study intends to compare genes that show differences in expression in the normal uterine lining areas of an endometriosis group and in the uterine linings of a normal group 
and classify their expression regulation patterns in functional terms.

\section{Materials and Methods}

\subsection{Selection of the Subjects}

Endometrial biopsy specimens were obtained from endometriosis patients and those with other diseases who underwent laparoscopy or laparotomy in the Department of Gynecology and Obstetrics of Seoul National University Hospital between January 2004 and December 2010. Among them, five endometriosis patients who were confirmed by laparoscopy or laparotomy as being in a moderate or severe stage according to the guidelines of American Society for Reproductive Medicine (1997) and five patients with no endometriosis detected in surgical findings and pathohistological examination were selected; their endometriums were qualified as being in the late secretory phase. Table 1 shows the endometriosis group's clinical characteristics. All 10 subjects were 40 years old or under, had a regular menstruation period ( 26 - 35 days), were not pregnant, and had no history of taking drugs. The Institutional Review Board for human research of each of the centers approved this project, and written informed consent was obtained from each participant.

\subsection{Collection of Endometrial Tissue and RNA}

A biopsy of endometrial tissue using the Wallace Endometrial Sampler or Novak Curette was taken from the uterus base of the subject. The tissue was transferred to a $4^{\circ} \mathrm{C}$ RNA later $(10 \mu \mathrm{l} / 1 \mathrm{mg}$ of tissue) and trizol reagent (Gibco) and $200 \mu \mathrm{l}$ chloroform (Sigma) were added to it. They were well mixed. Then the solution was centrifuged at $4^{\circ} \mathrm{C}$ at $12,000 \mathrm{rpm}$ for 15 minutes. Only its clear upper layer fluid was collected and it was moved it to a new tube. It was well mixed with an equivalent amount of isopropanol (Sigma) and the solution was maintained in a fixed state for 10 minutes. Then it was recentrifuged at $4^{\circ} \mathrm{C}$ at $12,000 \mathrm{rpm}$ for 15 minutes. Its upper layer fluid was discarded and $1 \mathrm{ml} 75 \%$ ethanol was added to

Table 1. Clinical characteristics of subjects: moderate/severe endometriosis group $(n=5)$.

\begin{tabular}{|c|c|c|c|c|c|}
\hline Patient ID & MCD\# & Age (yr) & Para & Stage & Chief complaints and findings \\
\hline $\mathrm{R} 2381$ & MCD \#25 & 38 & $1-0-1-1$ & Severe EMS & $\begin{array}{l}\text { Lower abdominal discomfort, } \\
\text { Ovarian mass, } \\
\text { Leiomyoma, severe adhesion, } \\
\text { s/p myomectomy }\end{array}$ \\
\hline R2392 & $\mathrm{MCD} \# 27$ & 32 & $0-0-1-0$ & Severe EMS & $\begin{array}{l}\text { Ovarian mass, } \\
\text { Recurrent EMS }\end{array}$ \\
\hline R2445 & $\mathrm{MCD} \# 23$ & 33 & $0-0-0-0$ & Moderate EMS & 1'infertility, Ovarian mass \\
\hline $\mathrm{R} 2563$ & $\mathrm{MCD} \# 23$ & 37 & $0-0-3-0$ & Moderate EMS & $\begin{array}{c}\text { Ovarian mass, } \\
\text { Leiomyoma, Adenomyosis }\end{array}$ \\
\hline $\mathrm{R} 2857$ & MCD \#27 & 33 & $1-0-0-1$ & Severe EMS & Ovarian mass \\
\hline
\end{tabular}

MCD: Menstrual count date; LSE: late secretory endometrium; EMS: endometriosis. 
it and mixed in. Then the solution was recentrifuged at $4^{\circ} \mathrm{C}$ at $8500 \mathrm{rpm}$ for 10 minutes and its upper layer fluid was removed. The sediments were air dried for 5 to 10 minutes and melted in $100 \mu \mathrm{l}$ nuclease-free water. The separated RNA quantity and absorption ratios (260/280 ratio and 260/230 ratio) were measured using the Nanodrop Spectrophotometer (ND-1000).

\subsection{Microarray and Data Analysis}

Total RNA was separated from the endometrial tissue and both cDNA and cRNA were cleaned up. Hybridization, detection, and scanning were performed according to the company Affymetrix's standard protocol. The robust multi-array average method using Affymetrix's GeneChip ${ }^{\circledR}$ Human Gene 1.0 ST array system was applied for data analysis. The raw intensity values were processed through background adjustment, normalization, and $\log 2$ transformation.

Among the standardized data that were $\mathrm{p}<0.01$ in the Student t-test, differentially expressed genes (DEG), defined to the standards of 1.5 fold changes and maximum expression levels at 6 or higher, in the endometriosis group and in the control group were analyzed.

A heat map that shows graphic information of the measured gene intensity values and a dendrogram that depicts the relationship between the groups were drawn. In order to differentiate similar patterns of gene expression, hierarchical clustering analysis was conducted according to the Ward-algorithmic method [11] [12] and the distances between each test group in expression degrees were calculated regarding expression degrees of DEG. Further, in order to assess the uncertainty in the hierarchical clustering analysis, the pvclust method was employed [13]; each group's statistical significance standards were identified based on approximately unbiased (AU) p-value and bootstrap probability (BP) value.

\subsection{Gene Oncology and Pathway Analysis}

Genes that had differences in expression, as identified by the analysis of genetic chip data, were classified by their functions, and a functional annotation cluster of them was made using Database for Annotation, Visualization, and Integrated Discovery (DAVID) software (http://david.abcc.ncifcrf.gov/summary.jsp) [14] [15]. Moreover, attempts to obtain more detailed visual information on pathways on which the genes acted were executed using the Kyoto Encyclopedia of Genes and Genomes (KEGG) pathway database connected with DAVID software.

\subsection{Verification of Gene Expression Data}

Genes with specific expression differences in the Affymetrix microarray analysis included CYP24A1 and MMP10, whose expressions have been known to increase in endometriosis patients by prior studies, GSTM5 and HOXA11, whose expressions have known to decrease in such patients by prior studies, and IGFBP1, whose results in this analysis conflicted with those from prior reports, were selected and 
Table 2. Sequences of the probes and primers for real time PCR.

\begin{tabular}{ccc}
\hline & Assay ID & Sequence \\
\hline MMP10 & Hs00233987_m1 & TTACAGGCATTTGGATTTTTCTACT \\
CYP24A1 & Hs00167999_m1 & TGCGGTGGAAACGACAGCAAACAGT \\
IGFBP1 & Hs00236877_m1 & TCACAGCAGACAGTGTGAGACATCC \\
HOXA11 & Hs00194149_m1 & GCCGGCGGCTCCAGTGGCCAACGCA \\
GSTM5 & Hs00757076_m1 & CTCCCGCTTTGAGGGTTTGAAGAAG \\
\hline
\end{tabular}

Annealing temperature: $60^{\circ} \mathrm{C}$.

their relative expressions were verified through quantitative real time polymerase chain reaction (PCR) using the ABI PRISM ${ }^{\circledR} 7000$ sequence detection system (SDS 7000, Perkin-Elmer Applied Biosystems, Lincoln, CA). As PCR master mix components, indicated end concentration $2.5 \mu \mathrm{l}$ water, $2.5 \mu \mathrm{l}$ forward primer $(9 \mu \mathrm{M})$, reverse primer $(9 \mu \mathrm{M}), 2.5 \mu \mathrm{l}$ probe $(2.5 \mathrm{uM})$, and $12.5 \mu \mathrm{l}$ TaqMan PCR 2x master mixture (applied biosystems) were prepared and 50 ng reverse transcribed total RNA in $5 \mu \mathrm{l}$ was added as a PCR template. Table 2 shows the used PCR primer and probe.

After the initial activation of uracil-N-glycosylase at $50^{\circ} \mathrm{C}$ for 2 minutes, AmpliTaq Gold was activated at $95^{\circ} \mathrm{C}$ for 10 minutes. The subsequent PCR conditions consisted of 45 cycles of denaturation at $95^{\circ} \mathrm{C}$ for 15 seconds and annealing and extension at $60^{\circ} \mathrm{C}$ for $1 \mathrm{~min}$ per cycle. During the PCR amplification, the amplified products were measured continuously through the determination of the fluorescence emission.

Gene expression was standardized on the basis of the GAPDH (VIC/MGB probe, primer limited) expression, corresponding to the $\mathrm{Ct}$ values of GAPDH by which cycle numbers (threshold cycle, $\mathrm{Ct}$ ) of detectable gene transcripts were denoted as delta $\mathrm{Ct}$. The relative quantitative value was expressed as $2^{\text {-deltadeltaCt}}$, in which DeltadeltaCt refers to the difference in the values of delta Ct between the test groups and the reference [16].

\section{Results}

\subsection{Analysis of Gene Chip Data}

In order to examine gene expression changes in relation to endometriosis, this study obtained the endometrial tissues of five endometriosis patients and five other patients with no endometriosis whose endometriums were in the late secretory phase. However, during Affymetrix GeneChip analysis, the array data of two patients that may be biological outliers were excluded and the endometrial tissues of the other three endometriosis patients and the control group were used. The excluded two subjects' clinical characteristics (R2563 and R2857 in Table 1) were not obviously different from those of the other three endometriosis patients (Table 1) and such outliers were verified to be neither a byproduct of graphic results that were not corrected through the Ward-algorithmic and Pvclust me- 
thods or a result of abnormal hybridization by the common reference probe (Figure 1).

Among a total of 18,633 genes obtained by Affymetrix GeneChip analysis, the expression of 462 genes increased (up-regulated) and the expression of 643 decreased (down-regulated), as selected by the standards of $\mathrm{p}<0.01$ in the Student t-test, 1.5 fold changes, and maximum expression levels at 6 or higher.

Genes whose expression increased in the endometrium tissues of female patients
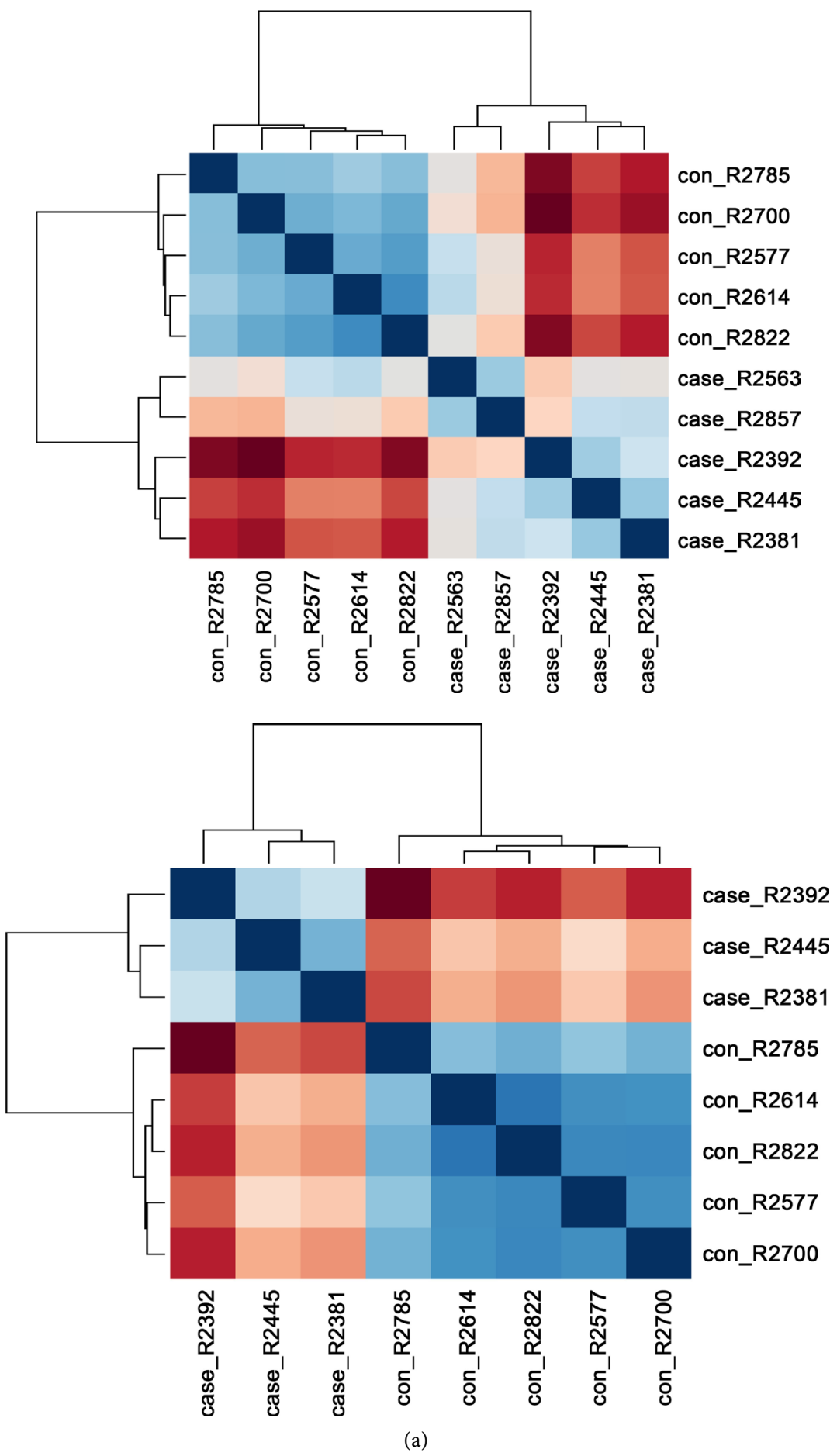

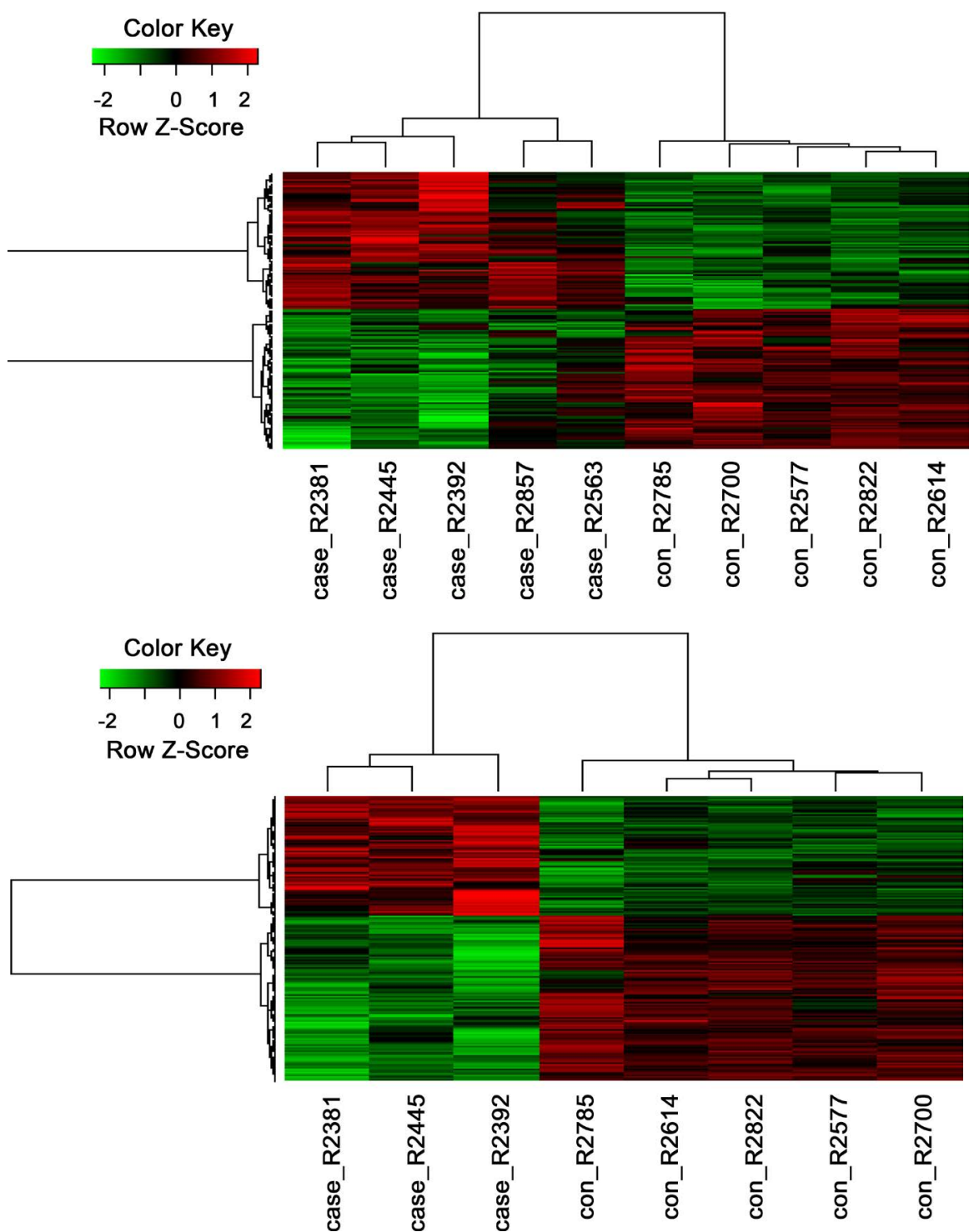

(b)

Cluster dendrogram with AU/BP values (\%)

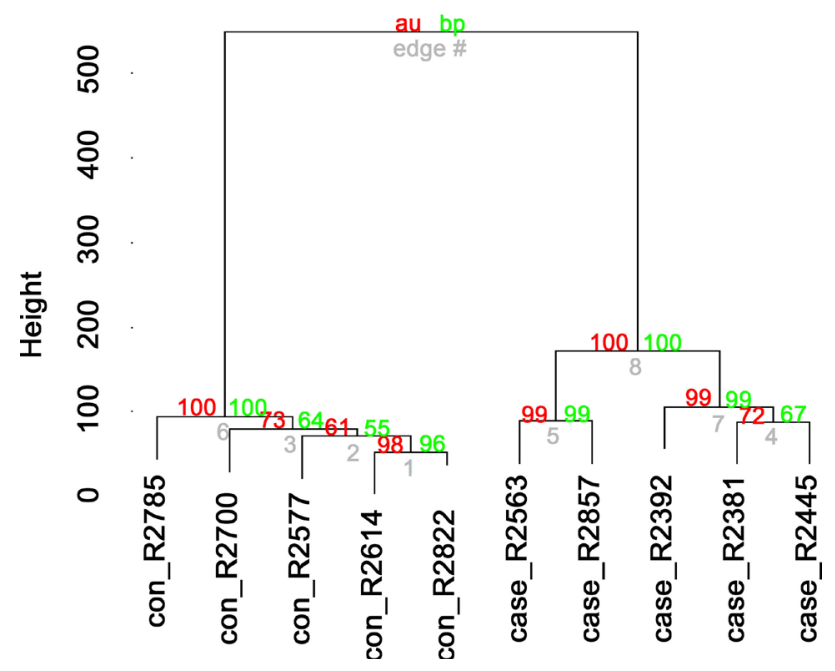




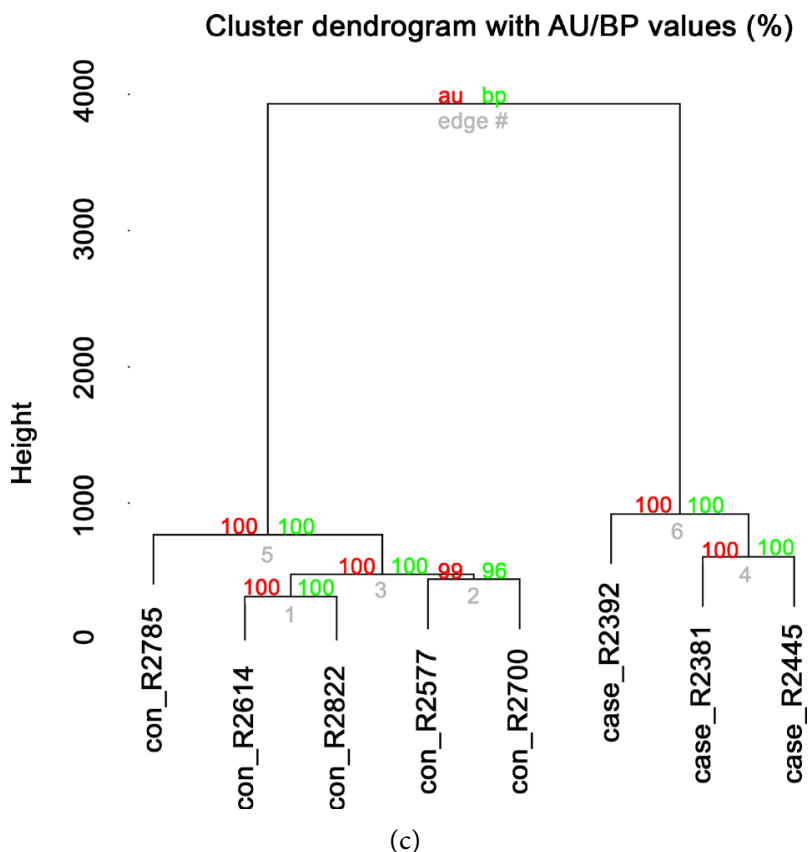

Figure 1. Analysis of endometrium data by microarray. (a) Distance between samples by Ward algorithm; (b) Heatmap. Red colors indicate relatively up-regulated genes compared to normal endometrium, green colors indicate relatively down-regulated genes compared to normal endometrium; (c) Statistical supports of hierarchical clustering. (AU: Approximately unbiased; BP: Bootstrap probability).

who developed endometriosis compared to the control group included matrix metalloproteinase 10 (MMP10), cytochrome P450, family 24, subfamily A polypeptide 1 (CYP24A1), matrix metalloproteinase 3 (MMP3), chemokine (C-C motif) ligand 20 (CCL20), Rho family GTPase 1 (RND1), interleukin 1-beta (IL1B), and insulin-like growth factor binding protein 1 (IGFBP1), and genes whose expression decreased were KIAA1210, serpin peptidase inhibitor, clade A (alpha-1 antiproteinase, antitrypsin), member 5 , insulin-like growth factor binding protein 5 endoplasmic reticulum aminopeptidase 2, ectonucleotide pyrophosphatase/ phosphodiesterase 3,Homeobox A11 (HOXA11), and glutathione S-transferase mu 5 (GSTM5).

\subsection{Gene Ontology (GO) Analysis Result Using DAVID Software}

Among the 462 genes whose expression increased by 1.5 fold or higher in the endometrium tissues of female patients who developed endometriosis compared to the control group, the GO group was selected; a biological process cluster consisting of 134 genes was selected. Annotation groups with great significance and high scored enrichment, characterized by their response to external stimulus, immune system process, positive regulation of cell motion, and angiogenesis, were observed (Table 3 ) and the part of the genes in this GO group whose expression increased are presented in Table 4.

Among the 643 genes whose expression decreased by 1.5 fold or higher in endometrium tissues of female patients who developed endometriosis compared to 
the control group, GO group was selected; a biological process cluster consisting of 109 genes was selected. Annotation groups involved in metabolic process, cellular ketone metabolic process, and ncRNA metabolic processing were observed

Table 3. Gene ontology groups with significant over-representation among genes with $\geq 1.5$ fold increased expression in endometriosis.

\begin{tabular}{clcc}
\hline Category & \multicolumn{1}{c}{ Specific GO Term } & No. of & $\begin{array}{c}\text { Enrichment } \\
\text { Genes }\end{array}$ \\
\hline GOTERM_BP_ALL & GO:0009605 response to external stimulus & 71 & 10.92 \\
GOTERM_BP_ALL & GO:0002376 immune system process & 57 & 9.69 \\
GOTERM_BP_ALL & GO:0051272 positive regulation of cell motion & 16 & 7.68 \\
GOTERM_BP_ALL & GO:0001525 angiogenesis & 19 & 6.86 \\
GOTERM_BP_ALL & GO:0042060 wound healing & 26 & 6.54 \\
GOTERM_BP_ALL & GO:0007165 signal transduction & 102 & 5.91 \\
GOTERM_BP_ALL & GO:0007275 multicellular organismal development & 104 & 5.38 \\
GOTERM_BP_ALL & GO:0006935 chemotaxis & 19 & 5.23 \\
GOTERM_BP_ALL & GO:0042127 regulation of cell proliferation & 41 & 5.07 \\
GOTERM_BP_ALL & GO:0006915 apoptosis & 34 & 4.99 \\
GOTERM_BP_ALL & GO:0030574 collagen catabolic process & 6 & 3.49 \\
\hline
\end{tabular}

Enrichment score*: To rank overall importance (enrichment) of gene group.

Table 4. Genes significantly highly up-regulated in endometriosis $(\mathrm{p}<0.01$, maximum expression $>6$ ).

\begin{tabular}{|c|c|c|c|}
\hline Gene name & Gene symbol & Gene ID & Fold change \\
\hline \multicolumn{4}{|l|}{ Collagen catabolic process } \\
\hline matrix metallopeptidase 10 & MMP 10 & 4319 & 89.0 \\
\hline matrix metallopeptidase 1 & MMP1 & 4312 & 9.4 \\
\hline matrix metallopeptidase 8 & MMP8 & 4317 & 5.3 \\
\hline \multicolumn{4}{|l|}{ Response to external stimulus } \\
\hline cytochrome P450, family 24 , subfamily A, polypeptide 1 & CYP24A1 & 1591 & 33.7 \\
\hline matrix metallopeptidase 3 & MMP3 & 4314 & 30.8 \\
\hline insulin-like growth factor binding protein 1 & IGFBP1 & 3484 & 15.9 \\
\hline interleukin 8 & IL8 & 3576 & 12.8 \\
\hline \multicolumn{4}{|l|}{ Immune system process } \\
\hline chemokine (C-C motif) ligand 20 & CCL20 & 6364 & 29.4 \\
\hline interleukin 1 , beta & IL1B & 3553 & 20.8 \\
\hline interleukin 1 , alpha & IL1A & 3552 & 7.7 \\
\hline intercellular adhesion molecule-1 & ICAM1 & 3383 & 7.0 \\
\hline \multicolumn{4}{|l|}{ Signal transduction } \\
\hline rho family GTPase 1 & RND1 & 27289 & 25.6 \\
\hline
\end{tabular}


Table 5. Gene ontology groups with significant over-representation among genes with $\geq 1.5$ fold reduced expression in endometriosis.

\begin{tabular}{cccc}
\hline Category & \multicolumn{1}{c}{ Specific GO Term } & No. of $\begin{array}{c}\text { Enrichment } \\
\text { Score }\end{array}$ \\
\hline GOTERM_BP_ALL & GO:0008152 metabolic process & 336 & 5.46 \\
GOTERM_BP_ALL & GO:0042180 cellular ketone metabolic process & 41 & 3.38 \\
GOTERM_BP_FAT & GO:0034660 ncRNA metabolic process & 21 & 2.58 \\
GOTERM_BP_FAT & GO:0016054 organic acid catabolic process & 15 & 2.49 \\
GOTERM_BP_ALL & GO:0006259 DNA metabolic process & 32 & 2.32 \\
GOTERM_BP_FAT & GO:0051186 cofactor metabolic process & 17 & 1.84 \\
GOTERM_BP_ALL & GO:0006629 lipid metabolic process & 42 & 1.82 \\
GOTERM_BP_FAT & GO:0022613 ribonucleoprotein complex biogenesis & 17 & 1.77 \\
GOTERM_BP_FAT & GO:0051276 chromosome organization & 28 & 1.51 \\
GOTERM_BP_ALL & GO:0006259 DNA metabolic process & 32 & 1.46 \\
\hline
\end{tabular}

Enrichment score*: To rank overall importance (enrichment) of gene group.

Table 6. Genes significantly highly down-regulated in endometriosis $(\mathrm{p}<0.01$, maximum expression $>6$ ).

\begin{tabular}{llcc}
\hline \multicolumn{1}{c}{ Gene name } & $\begin{array}{c}\text { Gene } \\
\text { symbol }\end{array}$ & $\begin{array}{c}\text { Gene } \\
\text { ID }\end{array}$ & $\begin{array}{c}\text { Fold } \\
\text { change }\end{array}$ \\
\hline Metabolic process & & & \\
KIAA1210 & KIAA1210 & 57,481 & -6.9 \\
serpin peptidase inhibitor, clade A (alpha-1 antiproteinase, antitrypsin), & SERPINA5 & 5104 & -5.6 \\
member 5 & & & -5.1 \\
insulin-like growth factor binding protein 5 & IGBBP5 & 3488 & -4.4 \\
endoplasmic reticulum aminopeptidase 2 & ERAP2 & 64,167 & -4.3 \\
ectonucleotide pyrophosphatase/phosphodiesterase 3 & ENPP3 & 5169 & -4.2 \\
synaptotagmin-like 5 & SYTL5 & 94,122 & -3.6 \\
homeobox A11 & HOXA11 & 3207 & -3.2 \\
3-hydroxy-3-methylglutaryl-Coenzyme A reductase & HMGCR & 3156 & -3.2 \\
glutathione S-transferase mu 5 & GSTM5 & 2949 \\
interleukin 20 receptor, alpha & IL20RA & 53,832 & -2.4 \\
\hline
\end{tabular}

(Table 5) and part of the genes in this GO group whose expression decreased are presented in Table 6.

\subsection{Pathway Analysis}

Among the genes whose expression increased or decreased, a total of 21 Kyoto Encyclopedia of Genes and Genomes (KEGG) pathways were identified (Table 7). In the case of the cytokine-cytokine receptor interaction pathway and the adipocyte signaling pathway, both genes with increased expression and decreased expression were denoted on a single map (Figure 2). 
Table 7. KEGG Pathways selected by DAVID analysis in endometriosis.

\begin{tabular}{|c|c|c|c|c|c|}
\hline Category & Term & Count & $\%^{*}$ & P Value ${ }^{t}$ & Genes \\
\hline \multicolumn{6}{|c|}{ Up-regulated } \\
\hline $\begin{array}{l}\text { KEGG }_{-} \\
\text {PATHWAY }\end{array}$ & $\begin{array}{l}\text { hsa04060:Cytokine-cytokine } \\
\text { receptor interaction }\end{array}$ & 28 & 7.272727273 & $5.42 \mathrm{E}-09$ & $\begin{array}{l}\text { CXCL1, TNFRSF21, TNFRSF12A, CSF1, CXCL2, TNFSF15, CCL8, } \\
\text { TNFRSF8, CX3CL1, TNFRSF11B, TNFRSF1B, IL23A, CCL20, } \\
\text { TNFRSF18, CSF3R, IL1B, CSF2RB, PRL, IL1A, IL2RA, IL8, OSM, } \\
\text { INHBA, IFNAR2, RELT, TNFRSF10D, CXCL16, PDGFRB }\end{array}$ \\
\hline $\begin{array}{l}\text { KEGG }_{-} \\
\text {PATHWAY }\end{array}$ & $\begin{array}{l}\text { hsa05200:Pathways in } \\
\text { cancer }\end{array}$ & 24 & 6.233766234 & $6.57 \mathrm{E}-05$ & $\begin{array}{c}\text { FGF18, PLD1, EPAS1, PTGS2, IL8, NFKBIA, NFKB2, BIRC3, } \\
\text { RALGDS, MMP1, SHH, IGF1R, RASSF5, CBLB, CDKN1A, } \\
\text { CDKN2B, LAMC3, ETS1, ITGAV, SLC2A1, CSF3R, PDGFRB, } \\
\text { RUNX1, FGF2 }\end{array}$ \\
\hline $\begin{array}{l}\text { KEGG }_{-} \\
\text {PATHWAY }\end{array}$ & $\begin{array}{l}\text { hsa04621:NOD-like } \\
\text { receptor signaling pathway }\end{array}$ & 10 & 2.597402597 & $6.83 \mathrm{E}-05$ & $\begin{array}{c}\text { CXCL1, NOD2, IL8, CXCL2, CCL8, NFKBIA, IL1B, RIPK2, } \\
\text { TNFAIP3, BIRC3 }\end{array}$ \\
\hline $\begin{array}{l}\text { KEGG }_{-} \\
\text {PATHWAY }\end{array}$ & $\begin{array}{l}\text { hsa04640:Hematopoietic } \\
\text { cell lineage }\end{array}$ & 10 & 2.597402597 & $7.80 \mathrm{E}-04$ & $\begin{array}{c}\text { IL2RA, GP1BB, ITGA5, CSF1, IL1B, CSF3R, ITGB3, IL1A, } \\
\text { HLA-DRA, CD7 }\end{array}$ \\
\hline $\begin{array}{l}\text { KEGG }_{-} \\
\text {PATHWAY }\end{array}$ & $\begin{array}{l}\text { hsa04610: Complement and } \\
\text { coagulation cascades }\end{array}$ & 8 & 2.077922078 & 0.003833629 & PLAT, C5AR1, CFB, F3, TFPI, PLAU, F2R, PLAUR \\
\hline $\begin{array}{l}\text { KEGG_- } \\
\text { PATHWAY }\end{array}$ & $\begin{array}{l}\text { hsa04666:Fc gamma } \\
\text { R-mediated phagocytosis }\end{array}$ & 8 & 2.077922078 & 0.020908628 & PLD1, MYO10, FCGR2C, CFL2, SPHK1, ASAP1, FCGR2A, FCGR3A \\
\hline $\begin{array}{l}\text { KEGG }_{-} \\
\text {PATHWAY }\end{array}$ & $\begin{array}{l}\text { hsa04810: Regulation of } \\
\text { actin cytoskeleton }\end{array}$ & 13 & 3.376623377 & 0.021870623 & $\begin{array}{l}\text { GNA13, FGF18, SSH1, MRAS, GNA12, ITGB3, ITGA5, ITGAV, } \\
\text { CFL2, ITGB6, PDGFRB, FGF2, F2R }\end{array}$ \\
\hline $\begin{array}{l}\text { KEGG }_{-} \\
\text {PATHWAY }\end{array}$ & $\begin{array}{l}\text { hsa04630:Jak-STAT } \\
\text { signaling pathway }\end{array}$ & 10 & 2.597402597 & 0.037676726 & $\begin{array}{l}\text { OSM, IFNAR2, CBLB, IL23A, IL2RA, SOCS3, PIM1, CSF2RB, } \\
\text { CSF3R, PRL }\end{array}$ \\
\hline $\begin{array}{l}\text { KEGG }_{-} \\
\text {PATHWAY }\end{array}$ & $\begin{array}{l}\text { hsa04920:Adipocytokine } \\
\text { signaling pathway }\end{array}$ & 6 & 1.558441558 & 0.045904686 & IRS2, TNFRSF1B, NFKBIE, SOCS3, SLC2A1, NFKBIA \\
\hline $\begin{array}{l}\text { KEGG }_{-} \\
\text {PATHWAY }\end{array}$ & $\begin{array}{l}\text { hsa04010:MAPK signaling } \\
\text { pathway }\end{array}$ & 14 & 3.636363636 & 0.046369117 & $\begin{array}{l}\text { FGF18, MRAS, RELB, GNA12, NFKB2, DUSP4, RASGRP1, } \\
\text { GADD45G, MAP3K8, IL1B, PDGFRB, NFATC2, FGF2, IL1A }\end{array}$ \\
\hline \multicolumn{6}{|c|}{ Down-regulated } \\
\hline $\begin{array}{l}\text { KEGG }_{-} \\
\text {PATHWAY }\end{array}$ & $\begin{array}{l}\text { hsa00280:Valine, leucine } \\
\text { and isoleucine degradation }\end{array}$ & 14 & 2.337228715 & $5.24 \mathrm{E}-10$ & $\begin{array}{l}\text { ALDH6A1, ACADM, BCAT2, EHHADH, BCKDHB, ACAT1, } \\
\text { ALDH3A2, HIBADH, DBT, ALDH7A1, IVD, MCCC1, OXCT1, } \\
\text { PCCB }\end{array}$ \\
\hline $\begin{array}{l}\text { KEGG }_{-} \\
\text {PATHWAY }\end{array}$ & $\begin{array}{l}\text { hsa00640:Propanoate } \\
\text { metabolism }\end{array}$ & 11 & 1.83639399 & $3.10 \mathrm{E}-08$ & $\begin{array}{l}\text { ALDH6A1, LDHB, ALDH7A1, ACADM, SUCLG2, EHHADH, } \\
\text { ACACA, ACSS2, ACAT1, PCCB, ALDH3A2 }\end{array}$ \\
\hline $\begin{array}{l}\text { KEGG }_{-} \\
\text {PATHWAY }\end{array}$ & $\begin{array}{l}\text { hsa00071:Fatty acid } \\
\text { metabolism }\end{array}$ & 9 & 1.502504174 & $3.05 \mathrm{E}-05$ & $\begin{array}{l}\text { CPT1C, ALDH7A1, ACADM, EHHADH, ADH5, ADH5P4, ACAT1, } \\
\text { ALDH3A2, DCI, CPT1A }\end{array}$ \\
\hline $\begin{array}{l}\text { KEGG }_{-} \\
\text {PATHWAY }\end{array}$ & $\begin{array}{l}\text { hsa00310:Lysine } \\
\text { degradation }\end{array}$ & 8 & 1.335559265 & $4.35 \mathrm{E}-04$ & $\begin{array}{l}\text { SETDB1, ALDH7A1, EHHADH, SETMAR, TMLHE, ACAT1, } \\
\text { ALDH3A2, SUV420H1 }\end{array}$ \\
\hline $\begin{array}{l}\text { KEGG_ } \\
\text { PATHWAY }\end{array}$ & $\begin{array}{l}\text { hsa00620:Pyruvate } \\
\text { metabolism }\end{array}$ & 7 & 1.168614357 & 0.001551163 & LDHB, ALDH7A1, ACACA, DLAT, ACSS2, ACAT1, ALDH3A2 \\
\hline $\begin{array}{l}\text { KEGG }_{-} \\
\text {PATHWAY }\end{array}$ & $\begin{array}{l}\text { hsa00010:Glycolysis/ } \\
\text { Gluconeogenesis }\end{array}$ & 8 & 1.335559265 & 0.002853392 & $\begin{array}{l}\text { LDHB, GALM, ALDH7A1, ADH5, DLAT, PFKM, ACSS2, ADH5P4, } \\
\text { ALDH3A2 }\end{array}$ \\
\hline $\begin{array}{l}\text { KEGG }_{-} \\
\text {PATHWAY }\end{array}$ & $\begin{array}{l}\text { hsa00650:Butanoate } \\
\text { metabolism }\end{array}$ & 6 & 1.001669449 & 0.003677294 & ALDH7A1, OXCT1, EHHADH, ACAT1, BDH1, ALDH3A2 \\
\hline $\begin{array}{l}\text { KEGG }_{-} \\
\text {PATHWAY }\end{array}$ & $\begin{array}{l}\text { hsa00072:Synthesis and } \\
\text { degradation of } \\
\text { ketone bodies }\end{array}$ & 3 & 0.500834725 & 0.031809524 & OXCT1, ACAT1, BDH1 \\
\hline $\begin{array}{l}\text { KEGG }_{-} \\
\text {PATHWAY }\end{array}$ & $\begin{array}{l}\text { hsa00410:beta-Alanine } \\
\text { metabolism }\end{array}$ & 4 & 0.667779633 & 0.031983898 & ALDH7A1, ACADM, EHHADH, ALDH3A2 \\
\hline $\begin{array}{l}\text { KEGG }_{-} \\
\text {PATHWAY }\end{array}$ & $\begin{array}{l}\text { hsa00380:Tryptophan } \\
\text { metabolism }\end{array}$ & 5 & 0.834724541 & 0.038178672 & ALDH7A1, CYP1B1, EHHADH, ACAT1, ALDH3A2 \\
\hline $\begin{array}{l}\text { KEGG_ } \\
\text { PATHWAY }\end{array}$ & $\begin{array}{l}\text { hsa00980:Metabolism of } \\
\text { xenobiotics by } \\
\text { cytochrome P450 }\end{array}$ & 6 & 1.001669449 & 0.0399123 & GSTA4, GSTM4, CYP1B1, GSTK1, ADH5, ADH5P4, GSTM5 \\
\hline
\end{tabular}

$\%^{*}$ : Number of genes involved in given term is divided by the total number of input genes; $p$ valuet: To examine the significance of gene-term enrichment with a modified Fisher's exact test. 


\subsection{Verification of Genes}

Among the genes whose expression increased or decreased in endometriosis tissues, the expression patterns of five types of genes, MMP10, IGFBP1, CYP24A1, HOXA11 and GSTM5, were verified with the real time PCR method. The samples used here were the same ones used in the gene chip experiment. With 2-deltadeltaCt of the control group used in the gene chip experiment assumed as 1 , fold changes in each endometriosis patient were identified.

The real time PCR expression of MMP10, IGFBP1, and CYP24A1 increased in all endometriosis patients, while that of GSTM5 decreased in all endometriosis patients. In the case of HOXA11, its expression in one patient did not decrease but the average value of the three patients showed an overall decreasing pattern
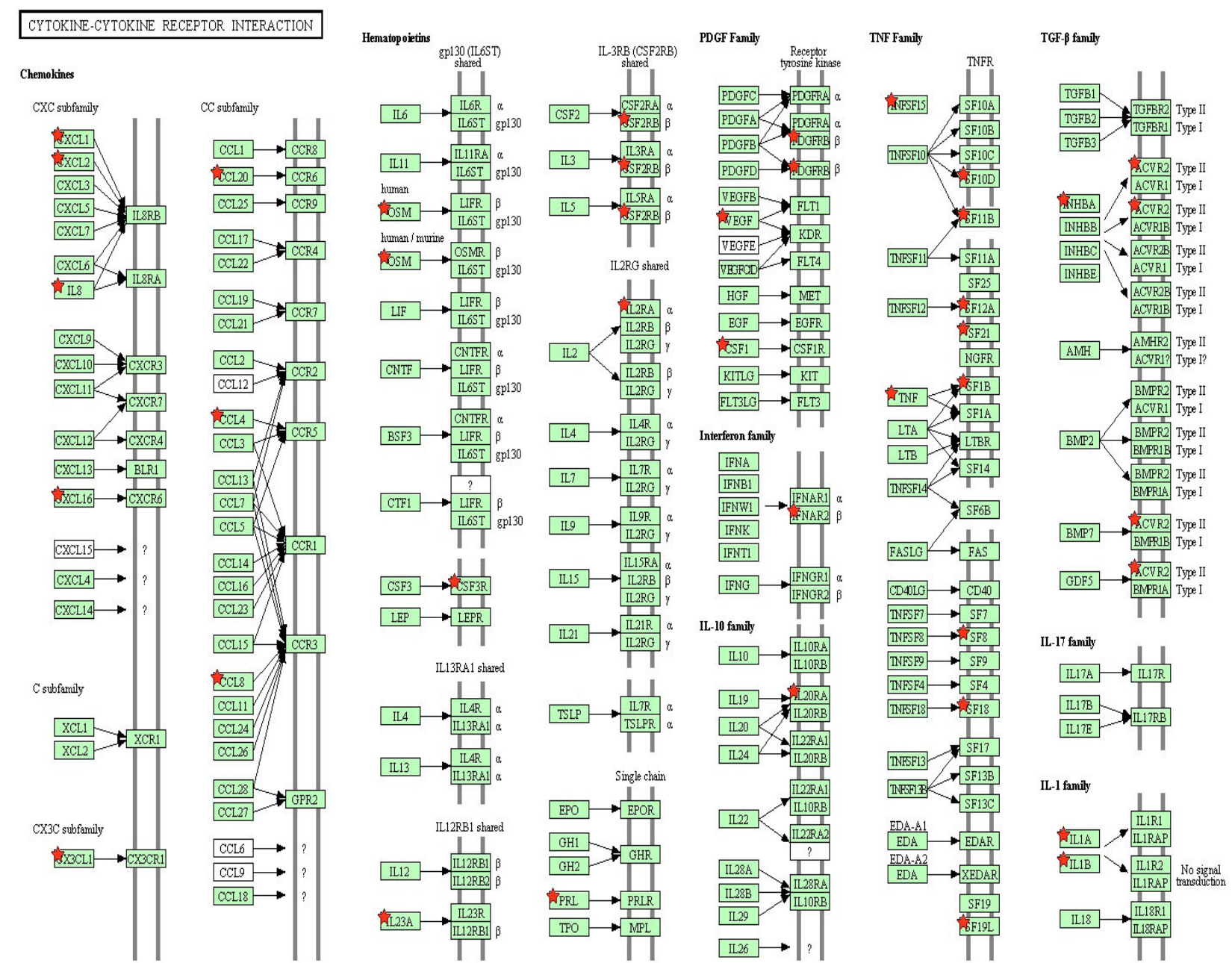

04060 9161010 (c) Kanehisa Laboratonies
(c)

CXCL: chemokine (C-X-C motif) ligand; IL-8: interleukin 8; CCL: chemokine (C-C motif) ligand; OSM: oncostatin M; CSF: colony stimulating factor; CSF3R: colony stimulating factor 3 receptor; CSF2RB: colony stimulating factor 2 receptor beta; IL2RA: interleukin 2 receptor alpha; TNF: tumor necrosis factor; TNFSF15: tumor necrosis factor superfamily member 15; SF1B: tumor necrosis factor superfamily member 1 B; IFNAR2: interferone alpha receptor 2; IL20RA: interleukin 20 receptor alpha; ACVR2: activin A receptor type II A, IIB.

(a) 


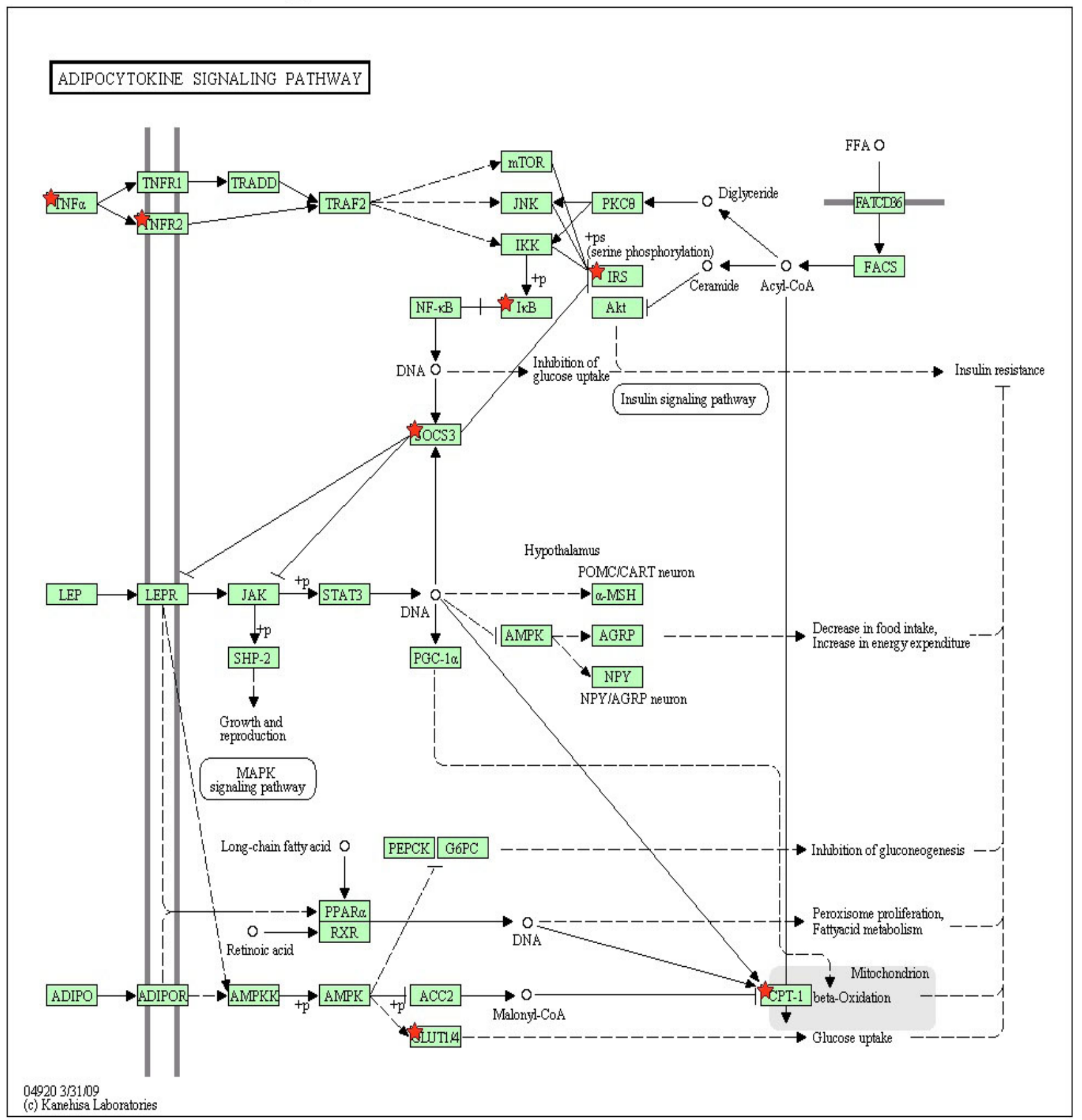

TNF $\alpha$ : tumor necrosis factor $\alpha$; TNFR: tumor necrosis factor receptor; IkB: nuclear factor of kappa light polypeptide gene enhancer in B-cells inhibitor; IRS: insulin receptor substrate; GLUT1,4: solute carrier family 2 (facilitated glucose transporter) member 1,4; CPT1: carnitine palmitoylitransferase 1.

(b)

Figure 2. Differential expression of genes involved in cytokine-cytokine receptor interaction (a) and adipocyte signaling pathway (b) in late secretory endometrium from women with $v s$. without endometriosis. In this diagram, each box represents a particular gene. Up-regulated genes are represented in red, whereas down-regulated genes are represented in blue. Diagram adapted from KEGG (http://www.genome.jp/kegg/). 
in expression, which was consistent with the gene chip experiment result (Table 8). Spearman's correlation method verified that changes in expression measured by the gene chip analysis and those measured by the real time PCR method were statistically and significantly correlated $\left(\mathrm{p}=0.037, \mathrm{R}^{2}=0.97\right)$ (Figure 3 ).

\section{Discussion}

Retrograde menstruation, coelomic epithelial cell metaplasia and lymphatic or vascular dissemination have all been put forward as possible hypotheses for the

Table 8. Real time PCR results in the mRNA levels of MMP10, IGFBP-1, CYP24A1, HOXA11, and GSTM5 in each case of the endometriosis group.

\begin{tabular}{cccccc}
\hline & \multicolumn{4}{c}{ Fold Change by PCR } & Fold Change by \\
Gene Symbol & R2381 & R2392 & R2445 & Case mean & Microarray \\
\cline { 2 - 5 } & 5716 & 629.2 & 455.3 & 2266.8 & 89.0 \\
MMP10 & 842.2 & 183.3 & 1099 & 708.2 & 33.69 \\
CYP24A1 & 191.3 & 97.23 & 17.96 & 102.2 & 15.86 \\
HOXA11 & 0.328 & 1.594 & 0.658 & 0.9 & -3.6 \\
GSTM5 & 0.461 & 0.142 & 0.219 & 0.3 & -3.2 \\
\hline
\end{tabular}

Values are fold change from control group.

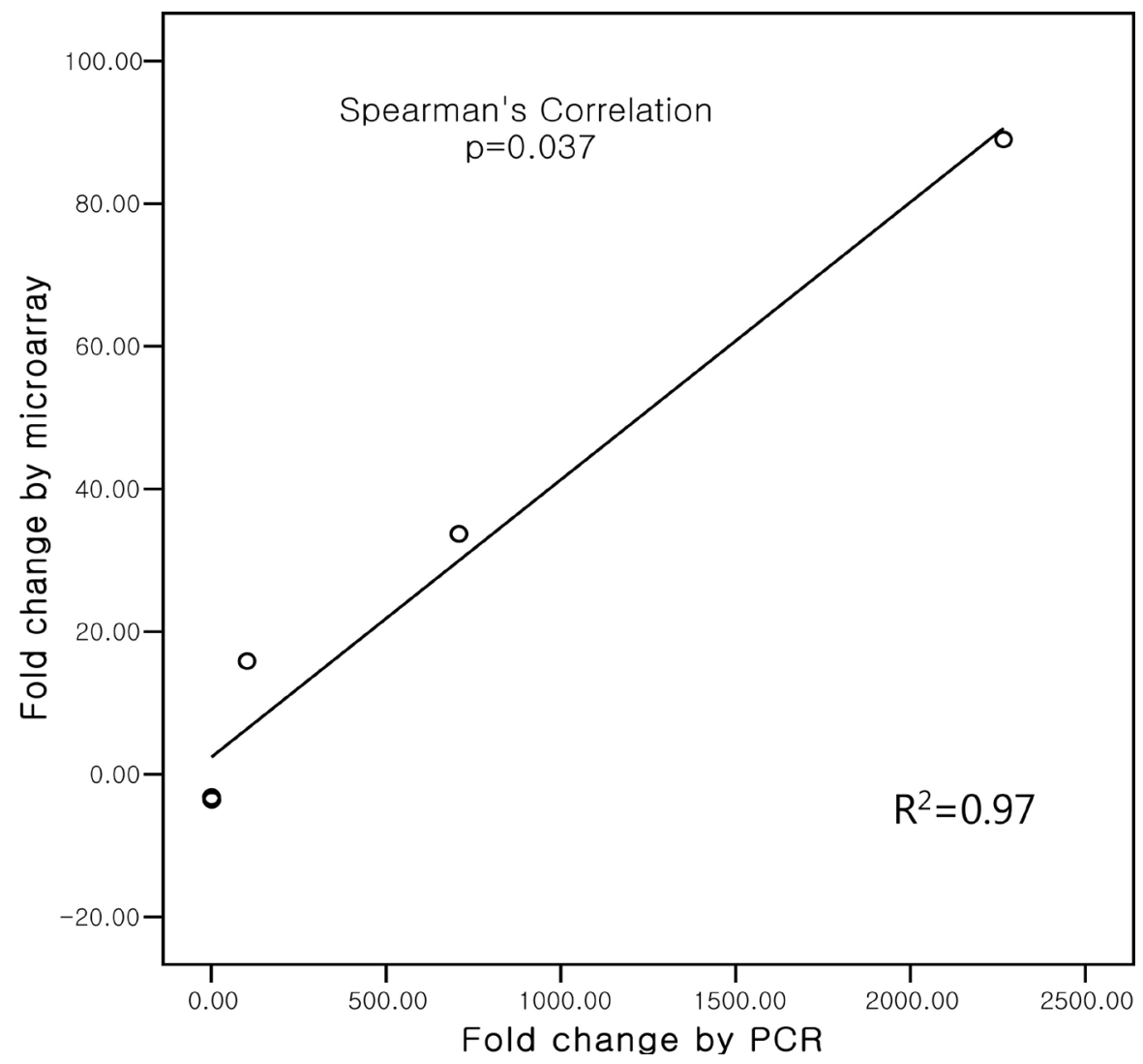

Figure 3. Relationship between fold changes in gene expression by microarray versus real time PCR. $\mathrm{R}^{2}=0.97$. 
pathogenesis of endometriosis. Genetic, immunologic, and environmental factors have also been found to be associated with endometriosis. However, the exact molecular mechanism of the development of endometriosis has not been elucidated. It has recently been proposed that there are differences between the endometrial tissues of women with endometriosis and those of normal women, and these may be the cause of infertility in these patients.

This study used the Affymetrix GeneChip system, which prints the genetic information directly onto a chip by photolithography. Compared to the conventional spotted oligonucleotide microarray, it offers excellent reproducibility and high specificity and sensitivity, and has many advantages in quantitative analysis.

In a study on the molecular mechanism of implantation problem in endometriosis, Giudice et al. reported that the products of specific genes were significantly decreased in the endometriosis group compared to the control group in the "window of implantation", which corresponds to the middle period of the secretory stage of the endometrium [8]. These genes were integrin $\alpha \mathrm{v}$ and $\beta 3$, leukemia inhibitory factor (LIF), HOXA-10 and HOXA-11. These genes show increased expression in the secretory stage in normal patients and play a key role in the establishment and maintenance of embryo implantation. However, they show decreased expression in endometriosis patients and may cause infertility due to failed implantation.

Studies that compared the eutopic endometria of endometriosis patients with a normal control group are listed in Table 9. Kao et al. used high-density oligonucleotide

Table 9. Gene expression microarray studies performed on human endometrial tissue.

\begin{tabular}{|c|c|c|c|c|c|c|}
\hline Study & $\begin{array}{l}\text { Cycle } \\
\text { phase }\end{array}$ & EMS stage & Subjects & Array reference & $\begin{array}{c}\text { No. of } \\
\text { Up-regulated genes }\end{array}$ & $\begin{array}{c}\text { No. of } \\
\text { Down-regulated genes }\end{array}$ \\
\hline Kao et al., 2003 & MSE & Mild/moderate & $\begin{array}{l}\operatorname{EMS}(+): 8 \\
\operatorname{EMS}(-): 7\end{array}$ & $\begin{array}{c}\text { Affymetrix } \\
\text { GeneChip Hu95A }\end{array}$ & $\begin{array}{l}91 \text { genes } \\
(\text { EST 28) }\end{array}$ & $\begin{array}{l}1150 \text { genes } \\
(\text { EST 29) }\end{array}$ \\
\hline Matsuzaki et al., 2005 & $\begin{array}{l}\text { LPE, } \\
\text { ESE, } \\
\text { MSE, } \\
\text { LSE }\end{array}$ & $\begin{array}{l}\text { Not defined/ } \\
\text { epithelial } \\
\text { vs stromal cell }\end{array}$ & $\begin{array}{l}\text { EMS (+):12 } \\
\text { EMS }(-): 12\end{array}$ & $\begin{array}{l}\text { Clontech ATLAS } \\
\text { HUMAN } 1.2 \text { cDNA } \\
\text { expression array }\end{array}$ & $\begin{array}{c}\text { Epithelial cell } \\
3 / 11 / 6 / 5 \\
\text { Stromal cell } \\
1 / 44 / 0 / 2\end{array}$ & $\begin{array}{l}\text { Epithelial cell } \\
1 / 28 / 8 / 20 \\
\text { Stromal cell } \\
7 / 7 / 12 / 1\end{array}$ \\
\hline Burney, et al., 2007 & $\begin{array}{l}\text { PE, } \\
\text { ESE. } \\
\text { MSE }\end{array}$ & Moderate/severe & $\begin{array}{l}\text { EMS }(+): 21 \\
\quad(6 / 6 / 9) \\
\text { EMS }(-): 16 \\
(5 / 3 / 3)\end{array}$ & $\begin{array}{c}\text { Affymetrix } \\
\text { Human U133-Plus } 2.0\end{array}$ & $\begin{array}{l}252 / 747 / 428 \\
(>1.5 \text { fold })\end{array}$ & $\begin{array}{c}447 / 1741 / 293 \\
(>1.5 \text { fold })\end{array}$ \\
\hline Sherwin et al., 2008 & LSE & $\begin{array}{c}\text { Minimal/mild } \\
\text { Moderate/severe }\end{array}$ & $\begin{array}{c}\text { EMS }(+) \text { : } \\
\quad 5 \rightarrow 4 \\
5 \rightarrow 4 \\
\text { EMS }(-): 6\end{array}$ & $\begin{array}{l}\text { Custom-made array, } \\
\text { University of Cambridge }\end{array}$ & $\begin{array}{c}8 \text { genes } \\
(\mathrm{p}<0.01,>1.75 \text { fold })\end{array}$ & $\begin{array}{c}1 \text { gene } \\
(\mathrm{p}<0.01,>1.75 \text { fold })\end{array}$ \\
\hline Chung et al., 2007 & $\begin{array}{l}\text { ESE } \\
\text { LSE }\end{array}$ & Not defined & $\begin{array}{l}\text { EMS (+):9 } \\
\quad(5 / 4) \\
\text { EMS }(-): 3\end{array}$ & $\begin{array}{l}\text { KNU } 4.8 \mathrm{~K} \text { cDNA } \\
\text { chip }\end{array}$ & $\begin{array}{l}\text { ESE: } 25 \text { genes } \\
\text { LSE: } 4 \text { genes }\end{array}$ & $\begin{array}{l}\text { ESE: } 25 \text { genes } \\
\text { LSE: } 1 \text { genes }\end{array}$ \\
\hline
\end{tabular}

PE, proliferative endometrium; SE, secretory endometrium; MSE, midsecretory endometrium; LPE, late proliferative endometrium; ESE, early secretory endometrium; LSE, secretory endometrium; EMS, endometriosis. 
microarrays to search genes that showed different expression levels between these two groups in the implantation phase. They confirmed these differences through reverse transcriptase polymerase chain reaction, Northern blot and dot blot analyses. As a result, they found that some genes showed increased expression in the normal endometrium in the implantation phase, but showed significantly low expression in endometriosis and vice versa. Thus, they claimed that the expression levels of these specific genes in endometriosis patients could be the cause of implantation problems or endometriosis [7]. In 2005, Matsuzaki et al. compared the genetic expression of the epithelial and matrix cells of the endometrium of normal women to those of women with severe endometriosis by cDNA expression array. They reported that in the late secretory stage, the expression levels of genes related to two signal transduction paths significantly increased [17].

The study by Chung et al. in 2007 is the only Korean study on the differences in gene expression in endometriosis and used the KNU $4.8 \mathrm{k}$ cDNA chip. They reported that genes associated with energy production, metabolism and signal transduction showed higher expression levels in endometriosis patients than in the control group and genes associated with the composition and function of the extracellular matrix showed lower expression levels. However, this study measured the expression level of a very small number of genes: 4 genes that showed increased expression and 1 gene that showed decreased expression in the late secretory stage. It is difficult from this result to determine whether endometriosis patients have significantly different expression profiles in the late secretory stage compared to the control group [18].

In 2008, Sherwin et al. used a custom made array to analyze the genetic expression profile in the endometrial tissues in the late secretory stage of 8 endometriosis patients (4 in minimal/mild stage and 4 in moderate/severe stage) and 6 control subjects. They found 8 genes that showed increased expression and 1 gene that showed decreased expression. They concluded that as there were no transcripts distinguishing between the minimal/mild stage and the moderate/severe stage, this did not provide a theoretical basis for the minimal invasive theory of endometriosis [19].

The present study found that in late stage endometriosis patients, the expression of 462 genes significantly increased, whereas the expression of 643 genes decreased. The genes that showed greatest increased expression levels in the endometrial tissues of women with endometriosis compared to the control group were matrix metalloproteinase 10 (MMP10), cytochrome P450 family 24 subfamily A polypeptide 1 (CYP24A1), matrix metalloproteinase 3 (MMP3), chemokine (C-C motif) ligand 20 (CCL20), Rho family GTPase 1 (RND1), interleukin 1-beta (IL1B), and insulin-like growth factor binding protein 1 (IGFBP1).

Matrix metalloproteinases (MMP) decompose extracellular matrix and assist the disruption of normal endometrium and the growth of new endometrium. The expression of MMP in endometrial tissue increases in the early menstrual cycle but is suppressed by the action of progesterone in the secretory stage. However, the expression of MMP during the secretory stage of endometriosis patients shows 
abnormal resistance to the suppression effect of progesterone. This allows endometrial cells that have been introduced into the abdominal cavity due to retrograde menstruation to invade the peritoneal surface and proliferate [20] [21] [22].

It has been reported that Intercellular adhesion molecules (ICAM-1) also decrease the activity of natural killer cells (NK cells) and the increasing concentration of soluble ICAM-1 in the abdominal cavity of endometriosis patients is associated with the decreasing activity of NK cells [23] [24]. Furthermore, ICAM-1 is separated from the cell surface by proteolytic cleavage of extracellular matrix; therefore the concentration of ICAM-1 in endometriosis lesions is associated with the expression of MMPs such as MMP-1 and MMP-9 [25] [26] [27]. This study also found increased expression of MMP-1 and ICAM-1 genes in late secretory stage endometrium in endometriosis patients, which lends weight to the theory that avoidance of immune surveillance is associated with the initial formation of endometriosis lesions.

The ectopic endometrium is known to be resistant to apoptosis. When exposed to the intra-abdominal environment, genes related to anti-apoptosis such as interleukin 1-beta (IL1B) and tumor necrosis factor alpha-induced protein 3 (TNFAIP3) increase to improve cell survival. The expression of genes related to chemokine activity and cytokine activity, as well as those related to the NF-kappa combination also increase, and this implies that defects in inflammatory response and signal transduction are involved in the pathogenesis of endometriosis.

IGFBP-1 is known to be a marker that is sensitive to the decidualization of matrix cells. In a study, the expression of IGFBP-1 in the endometrium of women with endometriosis in the window of implantation (middle of secretory stage) was compared to that of the control group [28]. However, it was only in the late secretory stage that expression was found to increase. In a study using immunocytochemistry and functional bioassay, Klemmt et al. reported that IGFBP-1 secreted from endometrial matrix fibroblasts cultured from women with endometriosis was decreased relative to normal women [29]. This may be associated with loss of endometrial differentiation capacity and could affect the proliferation and survival ability of endometrial cells in the heterotopic environment. Although this study has the limitation that progesterone was not used to induce decidualization and the cells were randomly obtained in various phases of the menstrual cycle, this finding suggests that the decidualization signal transduction system and endometrial receptivity could be affected in these patients. Kim et al. reported that HOXA10 mRNA increased in the normal endometrium of baboons with induced endometriosis, and that the expression of IGFBP1 mRNA showed a greater reaction to estradiol, medroxyprogesterone acetate and dibutyryl c-AMP compared to the endometrial matrix cells of normal baboons. Furthermore, they observed that HOXA10 in the matrix of cultured human endometrial cells in vitro decreased the level of IGFBP1 mRNA expression [30]. Therefore, HOXA10 should act contrary to the expression of IGFBP1 in decidualized cells and the decrease of HOXA10 in endometriosis may be partially related to the changing environment of the ute- 
rus.

Previously, it had been reported that IGFBP1 was expressed in the endometrium in the late secretory stage [31] and that baboons with induced endometriosis showed this phenotype rather than the phenotype of the middle secretory stage [32]. These results agree with the findings of this study that the expression of IGFBP1 in both the genetic chip analysis and quantitative real time PCR increased in the late secretory phase of the endometriosis patient group. It is not easy to understand the relationship of IGFBP1 to the receptivity of the endometrium, as this mechanism has not been clearly investigated. However, we can imply from these results that IGFBP1 could enter the abdominal cavity by retrograde flow and stimulate the proliferation of endometrial cells previously deposited there.

Genes that showed relatively decreased expression in the endometrial tissues of women with endometriosis were mainly associated with metabolic processes, such as ketogenesis and the generation of ncRNA. This could play a part in the development of endometriosis by creating an environment in which more menstrual blood flows backward into the abdominal cavity. It was found that the expression of glutathione S-transferase M5 (GSTM5), part of the phase II detoxification system, decreased. This enzyme removes toxic materials activated by the phase I enzyme CYP450 by combining them with glutathione. This could be significant, as there is a possibility that dioxin levels are connected to endometriosis.

There have been many recent studies on suppression resistance of estradiolinduced mitosis, which is mediated by progesterone in normal endometrial tissues, as well as attenuation mediated progesterone resistance. Burney et al. reported that the expression levels of the progesterone control genes (MIG6, FOXO1A, metallothionines, glycodelin, ILR1, and stanniocalcin) significantly decreased in the early and middle secretory stages, but decreased levels of progesterone in the late secretory stage were not associated with significantly decreased expression of these genes [28]. This suggests that the control mechanisms of progesterone secretion in endometriosis patients could vary between the early and middle secretory stages and the late secretory stage. Furthermore, it was found that the expression of the HOXA-11 gene is up-regulated in the window of implantation in normal endometrial tissue, but down-regulated for women with endometriosis [33]. Lee et al. reported that when the endometrium of normal mice was exposed to the endometriosis environment, the expression of progesterone-reactive genes (Hoxa10, Hoxa11) associated with the receptivity of the endometrium decreased [34].

In the above-described results obtained with high-density oligonucleotide microarrays, certain genes showed significantly different expression levels in endometriosis patients in progressed stages compared to the normal endometrium of the control group. A real-time PCR was conducted with the genes that showed increased expression in endometriosis such as CYP24A1 and MMP10, the genes 
that decreased expression such as GSTM5 and HOXA11, as well as the IGFBP1 gene, and it was found that they agreed with the results of the genetic chips in this study. As a high number of target groups would improve the power of study results and decrease the false discovery rate [35], the use of a relatively small number of samples in the microarray could be a limitation of this study. However, the significance is sufficient, considering that the existing studies on endometriosis patients experimented with similar sample sizes.

According to a recent review article, the inflammatory nature of endometriosis, accompanied by excess estrogen action, leads to a constellation of changes in the eutopic endometrium that interferes with normal embryo implantation. Also Signaling pathways associated with proliferation and cell survival are activated in endometriosis, and antiproliferative progesterone pathways are turned off [36]. Although endometrial receptivity is not impaired in women with endometriosis when healthy embryos reach the endometrial cavity [37], it seems clear that the eutopic endometrium of women with endometriosis biologically affect endometrial receptivity based on our results.

Furthermore, whereas existing studies compared the groups mainly in the implantation phase, focusing on infertility due to embryo implantation defects, this study used a high-density oligonucleotide microarray which can objectively analyze the pathogenesis of endometriosis and a large number of genes related to the pathophysiology in the late secretory stage which is presumed to be close to the time of retrograde menstruation.

The question still remains whether the interactions or differences between genes that show increased or decreased expression is the cause or result of endometriosis, and so studies are required to compare the genetic expression in each subdivided phase of menstrual cycle and which use more diverse bioinformatics. However, the confirmation of the existence of pathophysiologically meaningful genes in patients with endometriosis through microarray analysis both broadens our understanding of the pathogenesis of endometriosis and assists the development of noninvasive diagnosis techniques and new approaches to therapy.

\section{Competing Interests}

None of the authors have any competing interests.

\section{Funding}

This study was supported by a grant (01-PJ10-PG6-01GN13-0002) from the Korea Health 21 R\&D Project, Ministry of Health \& Welfare, and Republic of Korea.

\section{Author's Contribution}

Conceptualization: Choi, Y.M.;

Data curation: Hwang, K.R., Kim, J.J., Jeon, H.W., Hong, M.A.;

Investigation: Hwang, K.R., Choi, Y.M.;

Writing-original draft: Hwang, K.R., Choi, Y.M.; 
Supervision: Choi, Y.M., Kim, J.J.

\section{References}

[1] Giudice, L.C. and Kao, L.C. (2004) Endometriosis. The Lancet, 364, 1789-1799. https://doi.org/10.1016/S0140-6736(04)17403-5

[2] Kim, S.H., Chae, H.D., Kim, C.H. and Kang, B.M. (2013) Update on the Treatment of Endometriosis. Clinical and Experimental Reproductive Medicine, 40, 55-59. https://doi.org/10.5653/cerm.2013.40.2.55

[3] Sampson, J.A. (1927) Peritoneal Endometriosis Due to the Menstrual Dissemination of Endometrial Tissue into the Peritoneal Cavity. American Journal of Obstetrics \& Gynecology, 14, 422-469. https://doi.org/10.1016/S0002-9378(15)30003-X

[4] Pfeifer, S., Fritz, M.A., Goldberg, J., McClure, R., Lobo, R., Thomas, M., et al. (2012) Endometriosis and Infertility: A Committee Opinion. Fertility and Sterility, 98, 591-598. https://doi.org/10.1016/j.fertnstert.2012.05.031

[5] Prescott, J., Farland, L.V., Tobias, D.K., Gaskins, A.J., Spiegelman, D., Chavarro, J.E., et al. (2016) A Prospective Cohort Study of Endometriosis and Subsequent Risk of Infertility. Human Reproduction, 31, 1475-1482.

https://doi.org/10.1093/humrep/dew085

[6] Schena, M., Shalon, D., Davis, R.W. and Brown, P.O. (1995) Quantitative Monitoring of Gene Expression Patterns with a Complementary DNA Microarray. Science, 270, 467-470. https://doi.org/10.1126/science.270.5235.467

[7] Kao, L.C., Germeyer, A., Tulac, S., Lobo, S., Yang, J.P., Taylor, R.N., Osteen, K., Lessey, B.A. and Giudice, L.C. (2003) Expression Profiling of Endometrium from Women with Endometriosis Reveals Candidate Genes for Disease-Based Implantation Failure and Infertility. Endocrinology, 144, 2870-2881.

https://doi.org/10.1210/en.2003-0043

[8] Giudice, L.C., Telles, T.L., Lobo, S. and Kao, L.C. (2002) The Molecular Basis for Implantation Failure in Endometriosis: On the Road to Discovery. Annals of the New York Academy of Sciences, 955, 252-264. https://doi.org/10.1111/j.1749-6632.2002.tb02786.x

[9] Taylor, R.N., Lundeen, S.G. and Giudice, L.C. (2002) Emerging Role of Genomics in Endometriosis Research. Fertility and Sterility, 78, 694-698. https://doi.org/10.1016/S0015-0282(02)03325-3

[10] Giudice, L.C. (2003) Genomics' Role in Understanding the Pathogenesis of Endometriosis. Seminars in Reproductive Medicine, 21, 119-124. https://doi.org/10.1055/s-2003-41318

[11] Murtagh, F. (1983) A Survey of Recent Advances in Hierarchical Clustering Algorithms. The Computer Journal, 26, 354-359. https://doi.org/10.1093/comjnl/26.4.354

[12] Murtagh, F. and Legendre, P. (2014) Ward's Hierarchical Agglomerative Clustering Method: Which Algorithms Implement Ward's Criterion? Journal of Classification, 31, 274-295. https://doi.org/10.1007/s00357-014-9161-Z

[13] Suzuki, R. and Shimodaira, H. (2006) Pvclust: An R Package for Assessing the Uncertainty in Hierarchical Clustering. Bioinformatics, 22, 1540-1542. https://doi.org/10.1093/bioinformatics/btl117

[14] Dennis, G., Sherman, B.T., Hosack, D.A., Yang, J., Gao, W., Lane, H.C. and Lempicki, R.A. (2003) DAVID: Database for Annotation, Visualization, and Integrated Discovery. Genome Biology, 4, R60. https://doi.org/10.1186/gb-2003-4-9-r60 
[15] Huang, D.W., Sherman, B.T. and Lempicki, R.A. (2009) Systematic and Integrative Analysis of Large Gene Lists using DAVID Bioinformatics Resources. Nature Protocols, 4, 44-57. https://doi.org/10.1038/nprot.2008.211

[16] Livak, K. and Schmittgen, T. (2001) Analysis of Relative Gene Expression Data using Real-Time Quantitative PCR and the 2(-Delta Delta C(T)) Method. Methods, 25, 402-408. https://doi.org/10.1006/meth.2001.1262

[17] Matsuzaki, S., Canis, M., Vaurs-Barrière, C., Boespflug-Tanguy, O., Dastugue, B. and Mage, G. (2005) DNA Microarray Analysis of Gene Expression in Eutopic Endometrium from Patients with Deep Endometriosis using Laser Capture Microdissection. Fertility and Sterility, 84, 1180-1190. https://doi.org/10.1016/j.fertnstert.2005.04.041

[18] Chung, M.J., et al. (2007) Comparison of Gene Expression Profile in Eutopic Endometrium with or without Endometriosis: A Microarray Study. Korean Journal of Fertility and Sterility, 34, 19-31.

[19] Sherwin, J.R.A., Sharkey, A.M., Mihalyi, A., Simsa, P., Catalano, R.D. and D'Hooghe, T.M. (2008) Global Gene Analysis of Late Secretory Phase, Eutopic Endometrium Does Not Provide the Basis for a Minimally Invasive Test of Endometriosis. Human Reproduction, 23, 1063-1068.

https://doi.org/10.1093/humrep/den078

[20] Osteen, K.G., Rodgers, W.H., Gaire, M., Hargrove, J.T., Gorstein, F. and Matrisian, L.M. (1994) Stromal-Epithelial Interaction Mediates Steroidal Regulation of Metalloproteinase Expression in Human Endometrium. Proceedings of the National Academy of Sciences, 91, 10129-10133. https://doi.org/10.1073/pnas.91.21.10129

[21] Bruner, K.L., Matrisian, L.M., Rodgers, W.H., Gorstein, F. and Osteen, K.G. (1997) Suppression of Matrix Metalloproteinases Inhibits Establishment of Ectopic Lesions by Human Endometrium in Nude Mice. The Journal of Clinical Investigation, 99, 2851-2857. https://doi.org/10.1172/JCI119478

[22] Osteen, K.G., Yeaman, G.R. and Bruner-Tran, K.L. (2003) Matrix Metalloproteinases and Endometriosis. Seminars in Reproductive Medicine, 21, 155-164. https://doi.org/10.1055/s-2003-41322

[23] Oosterlynck, D.J., Meuleman, C., Waer, M., Vandeputte, M. and Koninckx, P.R. (1992) The Natural Killer Activity of Peritoneal Fluid Lymphocytes Is Decreased in Women with Endometriosis. Fertility and Sterility, 58, 290-295. https://doi.org/10.1016/S0015-0282(16)55224-8

[24] Fukaya, T., Sugawara, J., Yoshida, H., Murakami, T. and Yajima, A. (1999) Intercellular Adhesion Molecule-1 and Hepatocyte Growth Factor in Human Endometriosis: Original Investigation and a Review of Literature. Gynecologic and Obstetric Investigation, 47, 11-17. https://doi.org/10.1159/000052854

[25] Viganò, P., Gaffuri, B., Somigliana, E., Busacca, M., Di Blasio, A.M. and Vignali, M. (1998) Expression of Intercellular Adhesion Molecule (ICAM)-1 mRNA and Protein Is Enhanced in Endometriosis versus Endometrial Stromal Cells in Culture. Molecular Human Reproduction, 4, 1150-1156.

https://doi.org/10.1093/molehr/4.12.1150

[26] Mizumoto, H., Saito, T., Ashihara, K., Nishimura, M., Takehara, M., Tanaka, R., Ito, E. and Kudo, R. (2002) Expression of Matrix Metalloproteinases in Ovarian Endometriomas: Immunohistochemical Study and Enzyme Immunoassay. Life Sciences, 71, 259-273. https://doi.org/10.1016/S0024-3205(02)01641-7

[27] Hudelist, G., Lass, H., Keckstein, J., Walter, I., Wieser, F., Wenzl, R., Mueller, R., Czerwenka, K., Kubista, E. and Singer, C.F. (2005) Interleukin 1alpha and Tissue-Lytic 
Matrix Metalloproteinase-1 Are Elevated in Ectopic Endometrium of Patients with Endometriosis. Human Reproduction, 20, 1695-1701. https://doi.org/10.1093/humrep/deh794

[28] Burney, R., Talbi, S., Hamilton, A.E., Vo, K.C., Nyegaard, M., Nezhat, C., Lessey, B. and Giudice, L. (2007) Gene Expression Analysis of Endometrium Reveals Progesterone Resistance and Candidate Susceptibility Genes in Women with Endometriosis. Endocrinology, 148, 3814-3826. https://doi.org/10.1210/en.2006-1692

[29] Klemmt, P.A., Carver, J.G., Kennedy, S.H., Koninckx, P.R. and Mardon, H.J. (2006) Stromal Cells from Endometriotic Lesions and Endometrium from Women with Endometriosis Have Reduced Decidualization Capacity. Fertility and Sterility, 85, 564-572. https://doi.org/10.1016/j.fertnstert.2005.08.046

[30] Kim, J.J., Taylor, H.S., Lu, Z., Ladhani, O., Hastings, J.M., Jackson, K.S., Wu, Y., Guo, S.W. and Fazleabas, A.T. (2007) Altered Expression of HOXA10 in Endometriosis: Potential Role in Decidualization. Molecular Human Reproduction, 13, 323-332. https://doi.org/10.1093/molehr/gam005

[31] Fazleabas, A., Jaffe, R., Verhage, H., Waites, G. and Bell, S. (1989) An Insulin-Like Growth Factor-Binding Protein in the Baboon (Papio anubis) Endometrium: Synthesis, Immunocytochemical Localization, and Hormonal Regulation. Endocrinology, 124, 2321-2329. https://doi.org/10.1210/endo-124-5-2321

[32] Jones, C.J., Denton, J. and Fazleabas, A.T. (2006) Morphological and Glycosylation Changes Associated with the Endometrium and Ectopic Lesions in a Baboon Model of Endometriosis. Human Reproduction, 21, 3068-3080. https://doi.org/10.1093/humrep/del310

[33] Taylor, H., Bagot, C., Kardana, A., Olive, D. and Arici, A. (1999) HOX Gene Expression Is Altered in the Endometrium of Women with Endometriosis. Human Reproduction, 14, 1328-1331. https://doi.org/10.1093/humrep/14.5.1328

[34] Lee, B., Du, H. and Taylor, H.S. (2009) Experimental Murine Endometriosis Induces DNA Methylation and Altered Gene Expression in Eutopic Endometrium. Biology of Reproduction, 80, 79-85. https://doi.org/10.1095/biolreprod.108.070391

[35] Jørstad, T., Langaas, M. and Bones, A. (2007) Understanding Sample Size: What Determines the Required Number of Microarrays for an Experiment? Trends in Plant Science, 12, 46-50. https://doi.org/10.1016/j.tplants.2007.01.001

[36] Lessey, B. and Kim, J.J. (2017) Endometrial Receptivity in the Eutopic Endometrium of Women with Endometriosis: It Is Affected, and Let Me Show You Why. Fertility and Sterility, 108, 19-27. https://doi.org/10.1016/j.fertnstert.2017.05.031

[37] Miravet-Valenciano, J., Ruiz-Alonso, M., Gómez, E. and Garcia-Velasco, J.A. (2017) Endometrial Receptivity in Eutopic Endometrium in Patients with Endometriosis: It Is Not Affected, and Let Me Show You Why. Fertility and Sterility, 108, 28-31. https://doi.org/10.1016/j.fertnstert.2017.06.002 